\title{
DINÂMICA DA PRODUÇ̃̃O AGRÍCOLA NO MUNICÍPIO DE PALMITINHO / RS ENTRE OS ANOS DE 1988 E 2017
}

\author{
Viviane Capoane \\ Universidade Estadual de Mato Grosso do Sul, Curso de Geografia, Campo Grande, MS, Brasil \\ capoane@gmail.com
}

\begin{abstract}
RESUMO
Este trabalho objetivou analisar a dinâmica da produção agrícola nos últimos 30 anos e, os impactos ambientais associados, no município de Palmitinho, noroeste do Rio Grande do Sul. Os dados do período entre 1988 e 2017 foram obtidos no Sistema IBGE de Recuperação Automática. Mapas temáticos de uso e cobertura da terra, relevo e distribuição espacial das granjas de suínos e aviários foram gerados a fim de subsidiar a análise dos dados. No período analisado, a área utilizada para o plantio de culturas temporárias diminuiu $87,7 \%$. Parte dessas áreas foram convertidas em pastagens e o restante encontra-se em regeneração natural. Na pecuária, destacam-se a produção intensiva de suínos e aves e, a bovinocultura leiteira. As atividades agrícolas desenvolvidas no município, embora tenham grande importância econômica e social, têm provocado uma forte pressão sobre os recursos naturais, principalmente solo e água.
\end{abstract}

Palavras-chave: Sistemas intensivos. Lavoura. Pastagem. Degradação ambiental. Resíduos animais.

\section{DYNAMICS OF AGRICULTURAL PRODUCTION IN THE MUNICIPALITY OF PALMITINHO / RS BETWEEN 1988 AND 2017}

\begin{abstract}
This work aimed to analyze the dynamics of agricultural production in the last 30 years and the associated environmental impacts in the municipality of Palmitinho, northwest of Rio Grande do Sul. Data between 1988 and 2017 were obtained from the Sistema IBGE de Recuperação Automática. Thematic maps of land use and land cover, relief and spatial distribution of pig and poultry farms were generated in order to support data analysis. In the analyzed period, the area used for the planting temporary crops decreased by $87.7 \%$. Some of these areas were converted into pastures, and the rest being in natural regeneration. Livestock production stand out intensive production of pigs and poultry and, dairy cattle. The agricultural activities developed in the municipality, although of great economic and social importance, have caused a strong pressure on natural resources, mainly soil and water.
\end{abstract}

Keywords: Intensive systems. Tillage. Grassland. Environmental degradation. Animal waste.

\section{INTRODUÇÃO}

Antropólogos dizem que os primeiros seres humanos viviam em um estilo de vida de caçador-pescadorcoletor e que, há cerca de $10.000-7.000$ anos teria surgido a agricultura através da domesticação de animais e plantas (MAZOYER e ROUDART, 2009). Ao longo dos milênios, especialmente nos últimos 150 anos, inovações na agricultura (mecanização, biotecnologia, fertilizantes, defensivos agrícolas, dentre outras), levaram a notáveis aumentos na produção de alimentos, o que ajudou a sustentar a crescente população humana (FOLEY et al., 2005).

$\mathrm{Na}$ atualidade, a agricultura é um setor de grande importância que afeta a economia global, o bem-estar social e a vitalidade dos ecossistemas naturais (SONKA, 2016). Contudo, o crescimento da população mundial estimada para atingir nove bilhões de pessoas em 2050, têm aumentado a pressão sobre a produção agrícola mundial a fim de garantir a segurança alimentar (BOMMARCO; KLEIJN; POTTS, 2013; RAN et al., 2017). Até 2050, prevê-se que a procura por carne e produtos lácteos aumente em cerca de 70$80 \%$ e a procura por proteínas vegetais em 100-120\% (TILMAN et al., 2011; ALEXANDRATOS e 
BRUINSMA, 2012). Em 2016, as terras agrícolas ocupavam 4.873.157,48 hectares da superfície terrestre, sendo o continente Asiático com maior área, 34,1\%, seguido do continente Americano com 25,1\%, Africano com 23,2\%, Europeu com 9,6\% e Oceania com 7,9\% (FAO, 2019).

A produção pecuária é um dos setores agrícolas mais difundidos e, segundo Foley et al. (2011), utiliza cerca de $75 \%$ de todas as terras agrícolas sendo responsável por cerca de $30 \%$ das necessidades mundiais de água para fins agrícolas - irrigação, dessedentação animal e higienização (MEKONNEM e HOEKSTRA, 2012). Comparado com a produção de grãos, o uso da água no sistema de produção animal é geralmente muito alto, porque tanto o consumo direto de água pelos animais quanto a água usada para produzir a ração animal são computados (STEINFELD et al., 2006). Em geral, os sistemas pecuários representam cerca de $8 \%$ do consumo de água em todo o mundo (FAO, 2009).

No que tange aos impactos ambientais, o setor pecuário contribui com $14,5 \%$ das emissões globais de gases de efeito estufa (GERBER et al., 2013) e, a produção de suínos, é apontada como uma das principais contribuintes para a degradação ambiental, seja em nível global (efeito estufa) ou local (eutrofização, acidificação, etc.) (BASSET-MENS e VAN DER WERF, 2005). Os impactos diretos estão associados à poluição da água por nitratos, fósforo, matéria orgânica, microrganismos ou oligoelementos (MENZI et al., 2010; FOLEY et al., 2011), fármacos (VENGLOVSKY et al., 2009; BAILEY et al., 2015), poluição do ar por

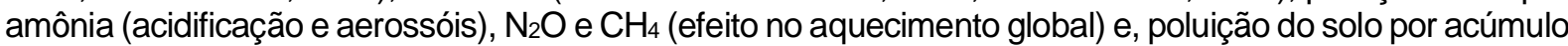
excessivo de fósforo ou elementos traço como cobre e zinco (CONTI et al., 2016).

Nas áreas utilizadas para a produção de grãos, que corresponde a $25 \%$ da área agrícola mundial (FOLEY et al., 2011), o problema reside no manejo inadequado dos solos, superfertilização e superdosagens de defensivos agrícolas. As consequências são o desmatamento, perda da diversidade de espécies, a perda da camada mais fértil do solo via erosão, contaminação do solo, degradação física, química e biológica do solo, diminuição da produtividade, assoreamento, poluição das águas e riscos à saúde humana e animal (TURCOTTE et al., 2017).

Na região noroeste do Rio Grande do Sul, a produção pecuária - suína, avicultura e a produção de leite e derivados - é uma atividade importante na economia dos municípios desde os tempos do povoamento. No entanto, a expansão dos setores agrícolas intensivos aliado ao manejo inadequado de lavouras e pastagens, contribuem para as emissões de gases de efeito estufa, degradação de terras agrícolas, poluição e eutrofização das águas superficiais, diminuição da biodiversidade, desequilíbrios nutricionais e, a perda de serviços ecossistêmicos, como a regulação hídrica em bacias hidrográficas e o controle da erosão. Diante do exposto, este trabalho teve como objetivo analisar a evolução da produção agrícola no período de 1988 a 2017 e, os impactos ambientais associados a atividade, no município de Palmitinho, noroeste do estado do Rio Grande do Sul.

\section{MATERIAL E MÉTODOS CARACTERIZAÇÃO DA ÁREA DE ESTUDO}

O município de Palmitinho localiza-se na região noroeste do estado do Rio Grande do Sul (Figura 1), e possui uma área de $144,045 \mathrm{~km}^{2}$. Conforme Rossato (2011), o clima da região corresponde ao subtropical muito úmido com inverno fresco e verão quente. A temperatura média anual varia entre $20-23^{\circ} \mathrm{C}$. A temperatura média do mês mais frio oscila entre $14-17^{\circ} \mathrm{C}$ e a temperatura média do mês mais quente varia entre $23-29^{\circ} \mathrm{C}$. Conforme essa autora, é a região com o conjunto de médias de temperaturas mais altas do estado. A precipitação fica entre 1700-1900 mm ao ano em 110-140 dias de chuva. As águas do município compõem duas bacias hidrográficas (BHs), sendo elas a $\mathrm{BH}$ do Rio Guarita com $68,4 \%$ do território e, a BH do Rio Pardo com 31,6\% (CAPOANE, 2015). Ambas as bacias são afluentes do Rio Uruguai.

A litologia é composta por basaltos da Formação Serra Geral, Fácie Paranapanema (DIAS e PARISI, 2007) e, as principais classes de solo do município são Luvissolo Crômico, Neossolo Litólico, Neossolo Regolítico e Cambissolo Háplico (CUNHA et al., 2010). O relevo do local é acidentado com encostas íngremes possuindo formas distintas como: espigões rochosos (28,7\%); espigões degradados $(1,16 \%)$; serras $(62,64 \%)$ com superfícies íngremes de relevo com aspecto muito rochoso, fortemente escarpadas e; vales (7,53\%) com terras quase planas ou aplainadas nos platôs e fundos de vale (CUNHA et al., 2010).

A fitofisionomia do Bioma Mata Atlântica na qual o município está inserido corresponde a Floresta Estacional Decidual (SOS Mata Atlântica/INPE, 2018). Esta fitofisionomia encontra-se bastante antropizada e os fragmentos mais bem preservados encontram-se em áreas onde não é possível a prática agrícola em função do relevo acidentado. 
Conforme Capoane et al. (2014), a ocupação agrícola está adaptada, principalmente, às dificuldades impostas pelo relevo. Os cultivos comerciais mais expressivos são fumo, milho e soja no verão, no período de inverno pequenas áreas são cultivadas com forrageiras e a maior parte fica em pousio hibernal. $\mathrm{Na}$ pecuária, conforme estes autores, destacam-se a produção de suínos, bovinocultura leiteira e avicultura, ou seja, a economia é dependente dos produtos primários, sendo basicamente agrícola com pecuária leiteira integrada a criação de suínos e aves. No município predominam pequenas propriedades que se fragmentaram ao longo do tempo, com agricultura de base familiar. Segundo os dados do último Censo Demográfico (IBGE, 2010), Palmitinho possui 6.920 habitantes e destes, 49\% residem na zona urbana e $51 \%$ na zona rural (CAPOANE; COSTA; KUPLICH, 2017a).

Figura 1 - Biomas do Rio Grande do Sul e localização do município de Palmitinho no estado (A) e; município de Palmitinho (B).

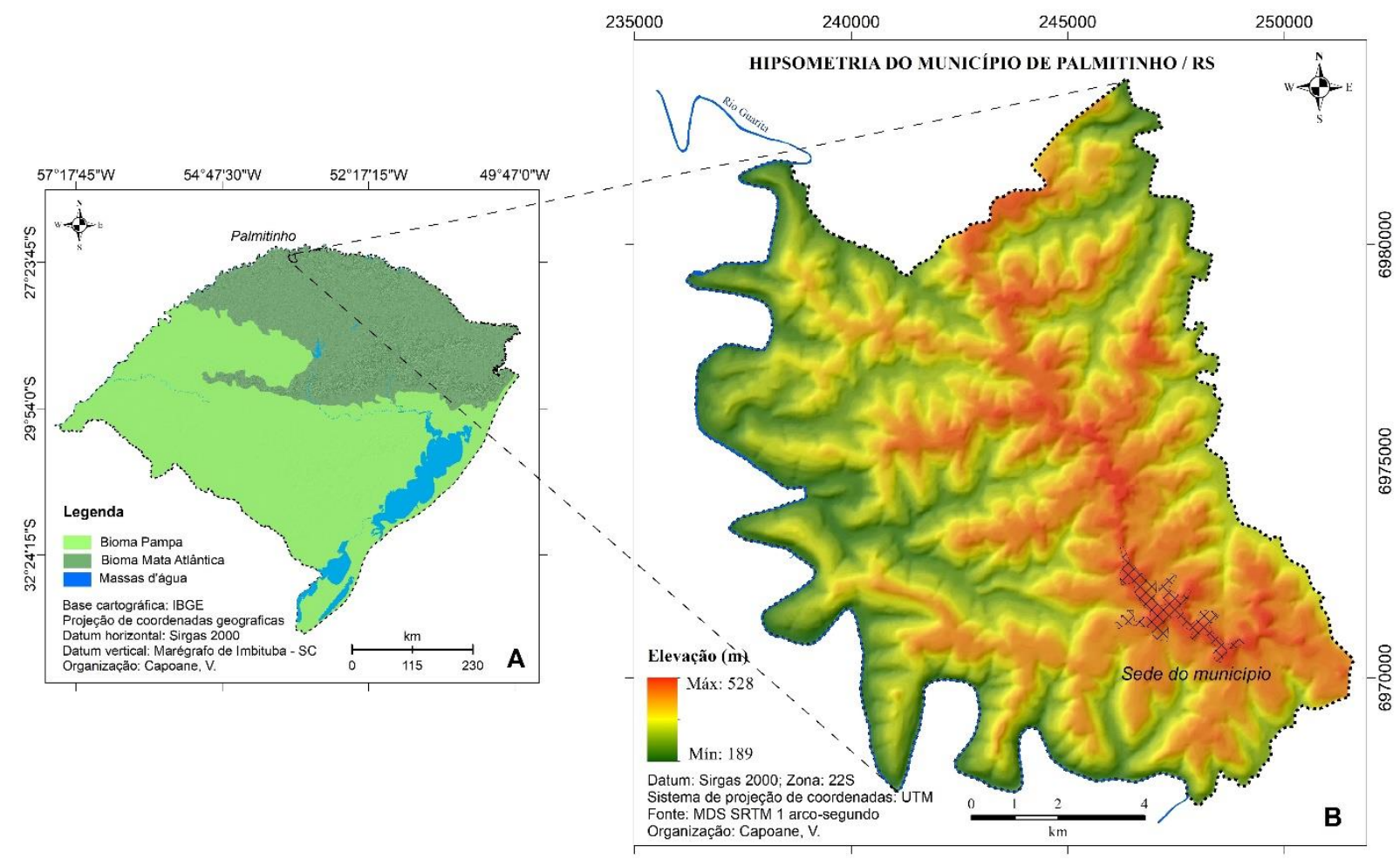

\section{Dados}

A dinâmica da agricultura, que conforme Lewis (2001), refere-se ao cultivo de plantas e criação de animais, foi analisada a partir de dados da área plantada com culturas temporárias e efetivo dos rebanhos para o período de 1988 a 2017. Os dados são disponibilizados pelo Instituto Brasileiro de Geografia e Estatística (IBGE), através do Sistema IBGE de Recuperação Automática (SIDRA): Produção Agrícola Municipal (PAM) - área plantada, área colhida, quantidade produzida, rendimento médio e valor da produção das lavouras temporárias (IBGE, 1988 a 2017a), e Produção Pecuária Municipal (PPM) - efetivo dos rebanhos, por tipo de rebanho (IBGE, 1988 a 2017b).

Os resultados são apresentados na forma de gráficos gerados no Microsoft $365 \AA$, aplicativo Excel, licenciado para a autora. Os mesmos também foram submetidos a análise estatística descritiva univariada e gráficos boxplot utilizando o programa livre Past (HAMMER; HARPER; RYAN, 2013). Para a geração do gráfico boxplot da PPM, os valores de cada variável foram tratados com base em Log10 buscando-se a linearização. Esse procedimento visa reduzir os efeitos de valores elevados entre os diferentes tipos de pecuária desenvolvidas no município.

\section{Mapas Temáticos}

A base cartográfica com o limite político e municipal corresponde ao mapeamento do Brasil ao milionésimo (IBGE, 2016). O mapeamento dos Biomas presentes no estado do RS corresponde ao Projeto de 
Sistematização das Informações sobre Recursos Naturais (IBGE, 2006). Os mapas hipsométricos, de relevo sombreado e de declividade foram gerados no programa livre de código aberto SAGA GIS 7.5.0 (CONRAD et al., 2015), a partir do Modelo Digital de Superfície (MDS) gerado por interferometria de radar na Shuttle Radar Topographic Mission (SRTM) no ano 2000. O MDS com precisão horizontal de 1 arco segundo é disponibilizado gratuitamente pelo Serviço Geológico dos Estados Unidos (USGS, 2019). A declividade foi separada em classes de acordo com os critérios da Embrapa (2006), sendo elas: 0-3\% relevo plano, $3-8 \%$ relevo suave ondulado, $8-20 \%$ ondulado, $20-45 \%$ relevo forte ondulado, $45-75 \%$ relevo montanhoso e $>75 \%$ relevo escarpado.

Para a análise qualitativa do uso e cobertura da terra foi gerado o Normalized Difference Vegetation Index (NDVI) utilizando imagens do satélite Sentinel-2, bandas B4 (Red) e B8 (NIR) de 22/03/2017 (ESA, 2017). As imagens utilizadas são disponibilizadas gratuitamente pela European Space Agency (ESA) no Hub de Pré-Operações. O programa livre utilizado para geração do NDVI foi o Sentinel Application Platform (SNAP), versão 7.0 (SNAP, 2019).

O arquivo georreferenciado com as granjas de suínos e aviários foi obtido em visita técnica na Secretaria Municipal da Agricultura e Meio Ambiente (SMAMA, 2018) do município de Palmitinho.

\section{RESULTADOS E DISCUSSÕES}

De 1988 a 2017 a área plantada com culturas temporárias no município de Palmitinho diminuiu 87,7\%, passando de 21.911 ha para 2.685 ha (Figura 2). A área mínima plantada foi de 2.685 ha em 2017 e a máxima de 28.549 ha em 1990. O coeficiente de variação (CV) para o período foi de $66,3 \%$, que, conforme Pimentel-Gomes (1985), corresponde a uma dispersão dos dados muito alta. A média do período foi de $11.428,1 \pm 1.383,9$ ha e o desvio padrão (DP) de 7.580,1.

Das 33 culturas temporárias que constam na lista do SIDRA da PAM, 17 foram computadas no município de Palmitinho em 1988 (Figura 3A) e, 15 em 2017 (Figura 3B). Arroz e abacaxi que constavam na lista do ano de 1988, não integravam a lista do ano de 2017 (Figuras 3A, B). Das sete principais culturas (Figura $3 C$ ), apenas o fumo teve aumento na área plantada (13,3\%), as demais culturas apresentaram queda significativa. Em ordem de decréscimo de área plantada estão: cana-de-açúcar, soja, trigo, milho, mandioca e feijão, com 95,8, 92,9, 91,0, 89,5, 78,6 e 71,2\%, respectivamente. Essas sete culturas ocupavam 97,1\% da área plantada com culturas temporárias no município no ano de 2017. A Figura 3D ilustra a distribuição do conjunto de dados das sete culturas por meio de um gráfico construído a partir de seus quartis: boxplot. Percebe-se que a maior amplitude de dados corresponde as culturas de milho e soja. Essas duas culturas também são as com maior área plantada em todo período analisado. Soja, feijão, mandioca e trigo, há valores que superam os limites de distribuição normal (99,3\% das observações - outlier).

Figura 2 - Evolução da área plantada (hectares) com lavouras temporárias no município de Palmitinho no período de 1988 a 2017.

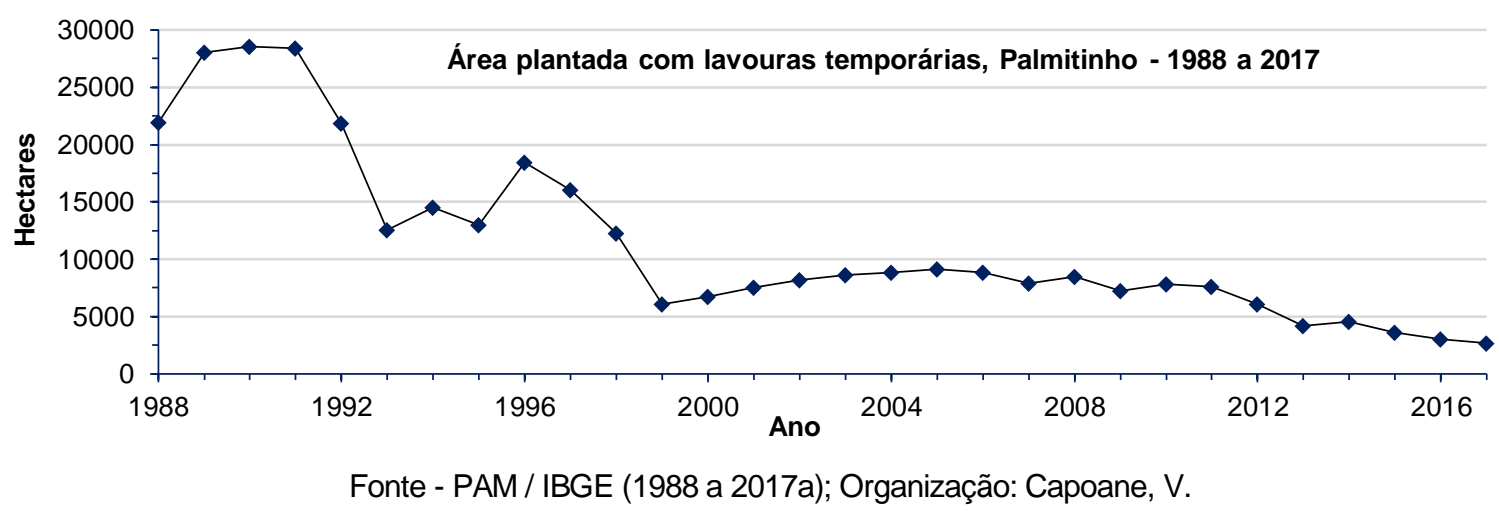

Com relação ao fumo, única cultura que apresentou incremento na área plantada no município no período analisado, trabalhos publicados por Rogério $L$. $L$ da Silveira, explicam como ocorreu o aumento na área plantada e na produção de fumo na região Sul do Brasil. Conforme Silveira (2015), o Brasil ocupa a posição de segundo maior produtor mundial de tabaco, e desde 1993 o posto de principal país exportador. Segundo

$\begin{array}{lllll}\text { Caminhos de Geografia } \quad \text { Uberlândia-MG } & \text { v. 21, n. } 78 \quad \text { Dez/2020 } & \text { p. 157-172 Página } 160\end{array}$ 
esse autor, a produção nacional concentra-se na região Sul, nos estados do Rio Grande do Sul e Santa Catarina, em pequenas propriedades familiares que são especializadas na produção de tabacos claros, divididos em dois grupos predominantes: o grupo estufa com destaque para o tabaco tipo Virgínia e o grupo dos tabacos de galpão, com destaque para o tipo Burley (tipo produzido em Palmitinho), ambos ideais para a confecção de cigarros. Para Silveira (2011), o que teria impulsionado a produção na região foi a intensificação da internacionalização do setor a partir da década de 1970, com o incremento dado aos tratos convencionais da agricultura e o advento tecnológico.

A produção da região, que em 1940 era de 27.507 toneladas (52\% da produção nacional), passou a 871.938 toneladas em 2006 (96,8\% da produção nacional) (SILVEIRA, 2011). Na safra de 2016/2017, a produção brasileira de tabaco foi de 880.881 toneladas e destas, 859.026 toneladas foram produzidas na região Sul (97,5\%). A maior área plantada também se encontra na região Sul, com 95\% (379.223 ha) do total nacional (IBGE, 2017). Conforme Trindade e Beppler (2020), quase a totalidade do tabaco produzido no país é exportado, principalmente para União Européia.

Para Silveira (2015) a estabilidade da economia brasileira e a oferta de financiamento bancário tornaram o tabaco brasileiro altamente competitivo e o beneficiamento industrial e a exportação de tabaco, um negócio altamente lucrativo às multinacionais que controlam oligopsonicamente essa atividade no território brasileiro. Para os pequenos agricultores, caso de Palmitinho, o sistema integrado da produção agroindustrial tabaqueira, com a garantia de venda da produção através de contratos, assistência técnica, assistência financeira, transporte do produto e, inexistência de uma melhor opção econômica de reprodução social, contribuem para que eles se mantenham no setor.

Além dos fatores acima mencionados, para Silveira (2015), o incremento da produção também se deve ao aumento da área plantada de tabaco que tem substituído gradativamente o cultivo de outras culturas tradicionais e de subsistência como a batata e o feijão, ou mesmo de outras culturas. No caso de Palmitinho, além da diminuição na área plantada de culturas de subsistência, a soja e o milho em pequenas propriedades, tem menor rentabilidade para os agricultores pela maior dificuldade de financiamento, custos de transporte e a incerteza do ponto de vista da comercialização, o que leva a substituição de tal cultura pelo tabaco, por conta da maior segurança e lucratividade que o sistema integrado de produção possui.

Figura 3 - Culturas temporárias nos anos de 1988 (A) e 2017 (B), evolução da área plantada (C) e boxplot (D) das sete principais culturas para o período analisado.

A

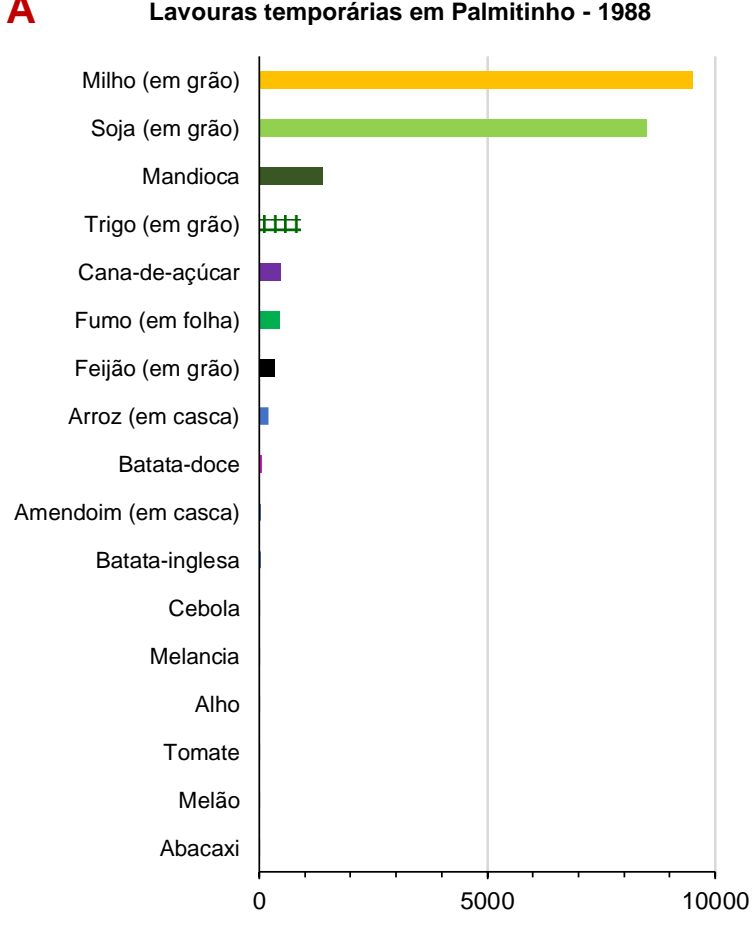

B Lavouras temporárias em Palmitinho - 2017

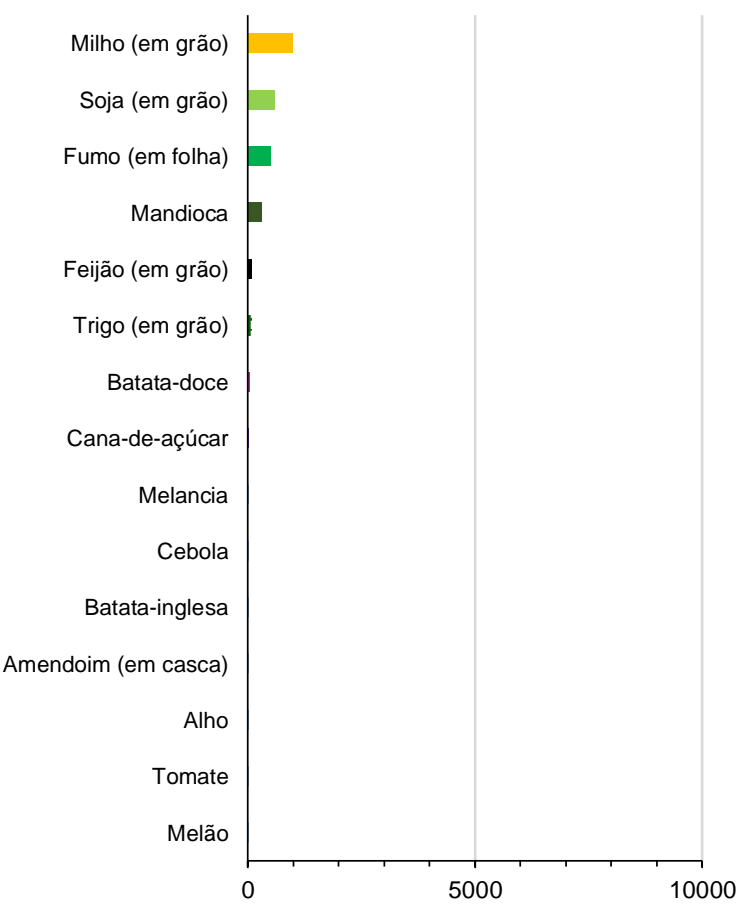




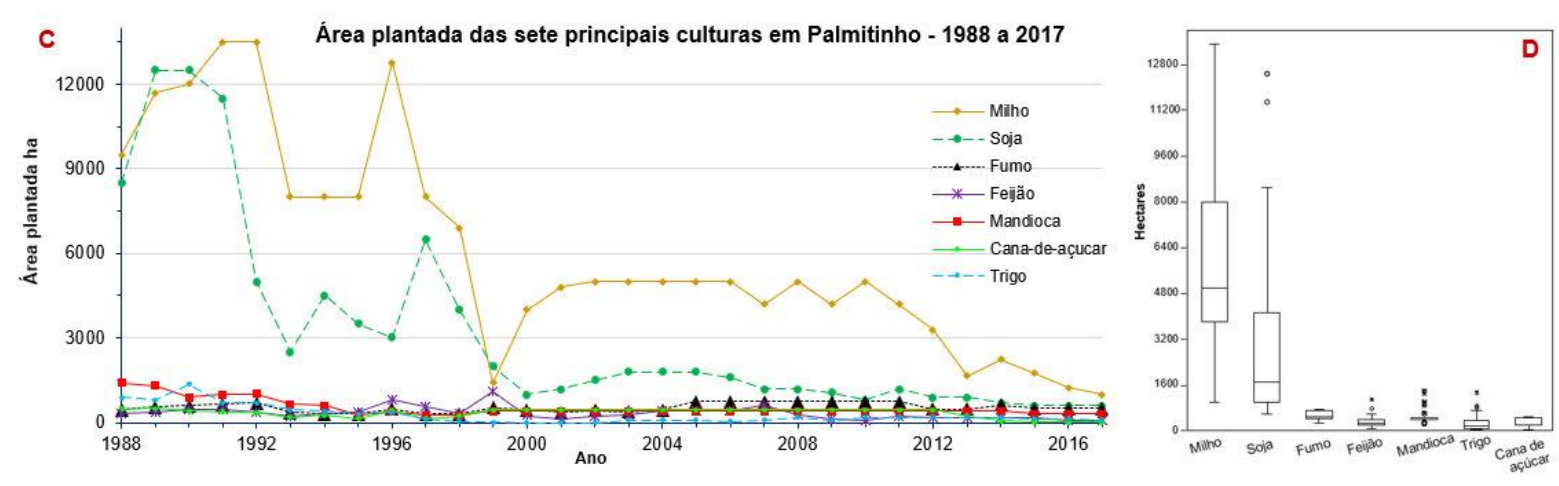

Fonte - PAM / IBGE (1988 a 2017a); Organização: Capoane, V.

$\mathrm{Na}$ Tabela 1 observa-se os resultados da estatística descritiva univariada para as sete principais culturas no período analisado. Soja e trigo foram as culturas que apresentaram maior dispersão de dados com CVs de 114 e 111, respectivamente. Das demais culturas, somente o fumo não apresentou dispersão dos dados muito alta (> 30\%), conforme Pimentel-Gomes (1985), enquadrando-se na classe de alta dispersão dos dados $(20-30 \%)$.

Tabela 1 - Estatística descritiva univariada da área plantada (hectares) de sete culturas no município de Palmitinho no período de 1988 a 2017.

\begin{tabular}{cccccccc}
\hline Culturas & Milho & Soja & Fumo & Feijão & Mandioca & Trigo & Cana-de-açúcar \\
\hline Mínimo & 1.000 & 600 & 300 & 80 & 250 & 20 & 20 \\
Máximo & 13.500 & 12.500 & 740 & 1.100 & 1.400 & 1.350 & 500 \\
Média & 6.029 & 3.217 & 530 & 334 & 510 & 276 & 345 \\
DP & 3.738 & 3.562 & 155 & 215 & 301 & 316 & 162 \\
Mediana & 5.000 & 1.700 & 510 & 290 & 400 & 175 & 460 \\
CV & 62 & 111 & 29 & 64 & 59 & 114 & 47 \\
\hline
\end{tabular}

DP: desvio padrão; CV: coeficiente de variação. Fonte: PAM / IBGE (1988 a 2017a); Organização: Capoane, V.

Na pecuária, destacam-se a produção de suínos, aves e a bovinocultura leiteira (Figura 4). Conforme a Emater/RS, em 2014 a suinocultura foi responsável por 70,3\% da arrecadação do imposto sobre mercadorias e serviços do município, envolvendo mais de 100 famílias na atividade. Os dados levantados mostram que em 2017 o plantel de suínos correspondia a 91.900 suínos entre as unidades de produção de leitões - UPL (matrizes) e nas unidades de terminação - UT (Figura 4A). A densidade demográfica de suínos do município em 2017 foi de 6,4 animais/ha, muito superior à densidade populacional que é de 0,48 habitantes/ha (IBGE, 2010). O predomínio do número de suínos em UTs, também justifica a queda na produção de milho e soja, pois a empresa integradora é quem arca com a alimentação dos animais.

A Figura 4B ilustra os sete tipos de pecuária desenvolvidas no município. A categoria caprino foi a única que apresentou valores que superam os limites de distribuição normal (99,3\% das observações). No período analisado o número mínimo de suínos foi de 13.929 animais (1996) e o máximo de 98.559 animais (2016). A média do período foi de 38.603 e o DP de 2.589. A dispersão dos dados enquadra-se na classe muito alta, $>30 \%$ (PIMENTEL-GOMES, 1985). A estatística descritiva univariada para o período analisado pode ser visualizada na Tabela 2. 
Figura 4 - Evolução da pecuária no município de Palmitinho no período de 1988 a 2017.
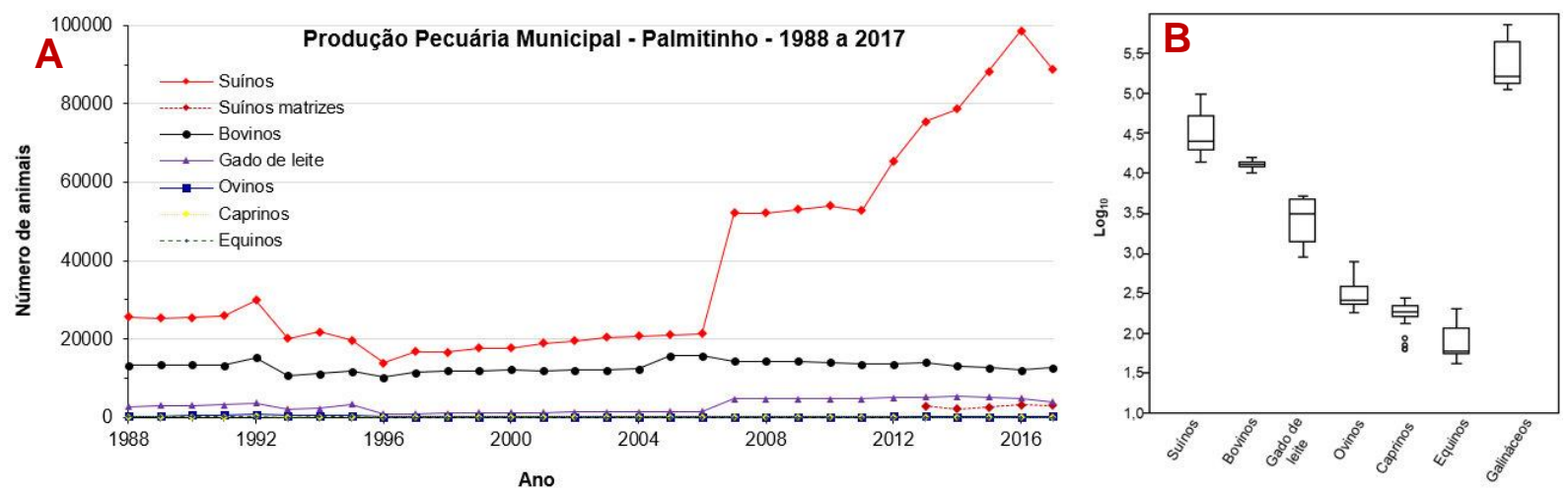

Fonte - PPM / IBGE (1988 a 2017b); Organização: Capoane, V.

A distribuição espacial das granjas de suínos pode ser visualizada na Figura 5. Nota-se que muitas granjas encontram-se próximas a rede de drenagem, o que configura riscos aos ecossistemas aquáticos, pois como constatado por Capoane et al. (2014) em trabalho desenvolvido em uma sub-bacia do Rio Guarita inserida no município de Palmitinho, os sistemas de armazenamento de efluentes, na maioria das propriedades, são subdimensionados.

O número de bovinos (Figura 4) apresentou pequeno CV (<10\%) com 9,1\% (Tabela 2) no período analisado, o que indica baixa dispersão dos dados; o número de ovinos e equinos apresentaram $\mathrm{CV}$ médio (10 a 20\%) com 13\% e 13,2\%, respectivamente; caprinos, gado leiteiro e suínos apresentaram CVs muito altos (>30\%) com $42,1 \% ; 50,2 \%$ e $56,2 \%$, respectivamente.

Tabela 2 - Estatística descritiva univariada da Produção Pecuária Municipal no município de Palmitinho no período de 1988 a 2017.

\begin{tabular}{cccccccc}
\hline Tipos & Suínos & Bovinos & Gado de leite & Ovinos & Caprinos & Equinos & Galináceos \\
\hline Mínimo & 13.929 & 10.200 & 898 & 182 & 63 & 42 & 112.530 \\
Máximo & 98.559 & 15.701 & 5.300 & 764 & 275 & 200 & 727.870 \\
Média & 38.603 & 12.958 & 3.041 & 322 & 178 & 87 & 308.367 \\
DP & 2.589 & 1.399 & 1.607 & 146 & 60 & 51 & 242.194 \\
Mediana & 25.370 & $12.902,5$ & 3.096 & 258 & 183 & 60 & 165.330 \\
CV & 67 & 11 & 53 & 45 & 34 & 58 & 78 \\
\hline
\end{tabular}

DP: desvio padrão; CV: coeficiente de variação. Fonte: PPM / IBGE (1988 a 2017b); Organização: Capoane, V. 
Figura 5 - Distribuição espacial dos aviários e granjas de suínos no município de Palmitinho.

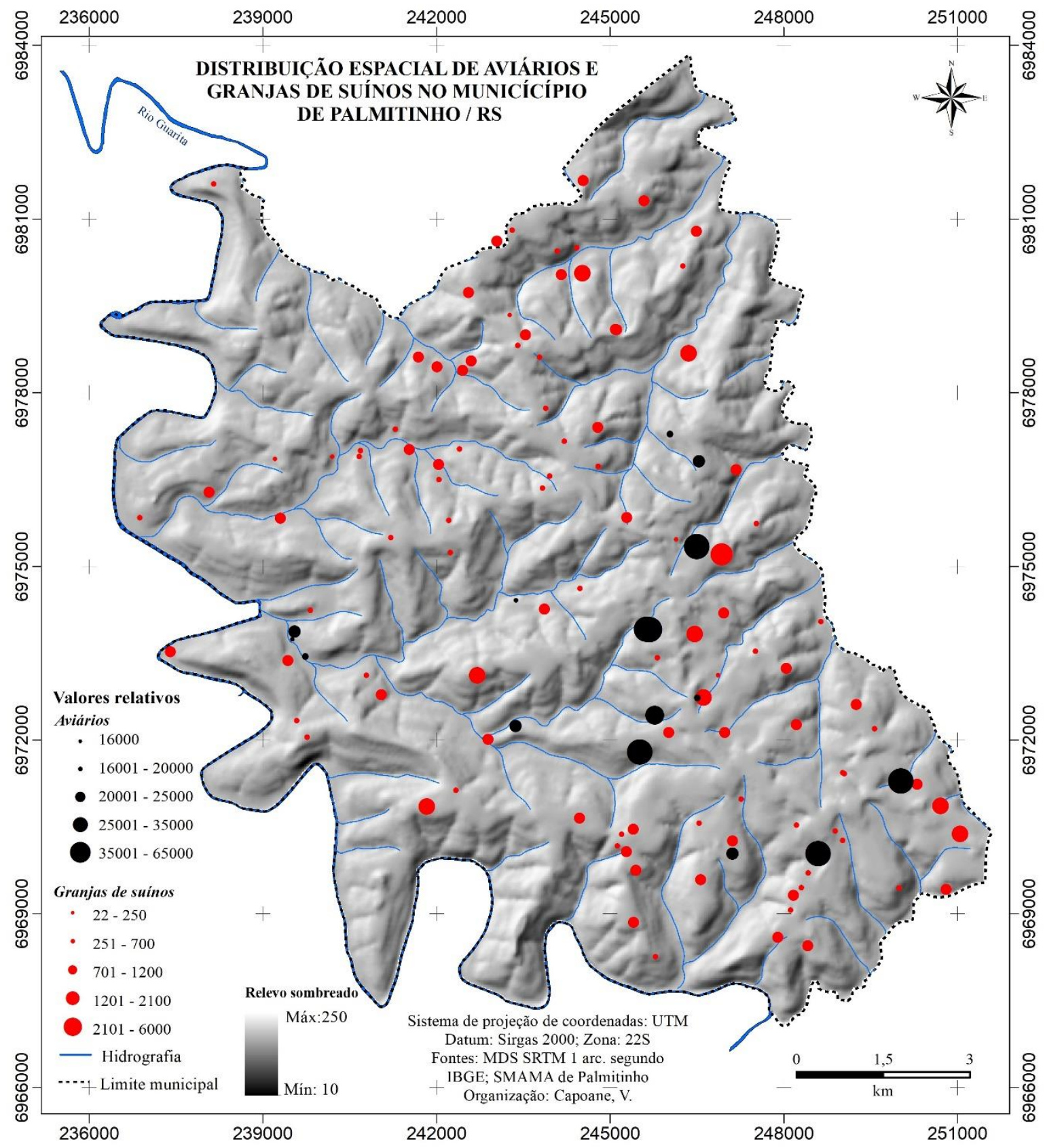

Na pecuária leiteira (Figura 6), o CV mostra uma dispersão de dados muito alta (53\%) (Tabela 2). De 1988 a 2017 o número mínimo de vacas ordenhadas foi de 898 cabeças (1997) e o máximo de 5.300 (2014), com média de 3.041 e DP de 1.607. De 1988 a 1995 houve uma dispersão média dos dados (18,3\%). Entre 1995 e 1996 houve uma queda de 28,9\% no número de cabeças. Nesse intervalo a produção de leite teve comportamento similar ao do número de vacas ordenhadas. De 1996 a 2006, o número de animais e o leite produzido apresentaram pequena variação, e a produção era baixa (Figura 6). Entre 2006 e 2007 houve um aumento de $208,30 \%$ no número de vacas ordenhadas. O aumento no número de cabeças também veio acompanhado de um aumento significativo na produção de leite $(208,26 \%)$, como mostra a Figura 6 . Considerando o período analisado, 30 anos, o número de cabeças aumentou $46,4 \%$ e a quantidade de leite produzida $413,2 \%$.

O aumento na produção de leite no município é atribuído ao aumento da área de pastagens através da conversão de áreas anteriormente utilizadas para o plantio de milho e soja, silagem para o período de 
inverno e, melhoramento genético. O mesmo foi constatado por Milani (2011) em trabalho desenvolvido na região noroeste do RS. Segundo essa autora, os produtores de leite do Rio Grande do Sul têm investido cada vez mais em alimentação, animais com genética apurada, além de investimentos em infraestrutura que resultam em uma maior produtividade. Essas alterações realizadas pelos produtores rurais em seus sistemas de produção têm aumentado cada vez mais a área destinada à atividade leiteira na região (MARASCHIN, 2004; OLIVEIRA, 2010).

Conforme Casali (2012), a mesorregião Noroeste do RS, onde está inserido o município de Palmitinho, possui a maior concentração de produtores de leite do estado, tendência consolidada na última década, combinando o cultivo de soja, milho e trigo com a pecuária leiteira, como forma de complementação da renda. Para este autor, outro fator que contribuiu foi a proximidade da agroindústria com tecnologia UHT (ultra high temperature), o que desobriga a instalação das unidades produtoras próximas aos grandes centros consumidores.

Com relação aos impactos ambientais relacionados a essa atividade, Capoane et al. (2016) em trabalho desenvolvido em uma sub-bacia do Rio Guarita no município de Palmitinho, avaliando a qualidade de sedimento de leito, os autores concluíram que esta atividade também contribui para a degradação dos ecossistemas aquáticos. Conforme estes autores, na maioria das propriedades que desenvolvem a atividade, não há sistema de armazenamento dos efluentes gerados nas salas de ordenha, os mesmos são lançados diretamente no ambiente. Nas propriedades onde a atividade está consorciada com a suinocultura, o efluente gerado na sala de ordenha é direcionado para as esterqueiras, e posteriormente utilizado como fertilizante nas lavouras e pastagens. Também há propriedades em que a ordenha é feita a céu aberto, o que potencializa a degradação do solo e, em eventos de chuva, da água.

Figura 6 - Vacas ordenhadas e leite produzido no município de Palmitinho no período de 1988 a 2017.

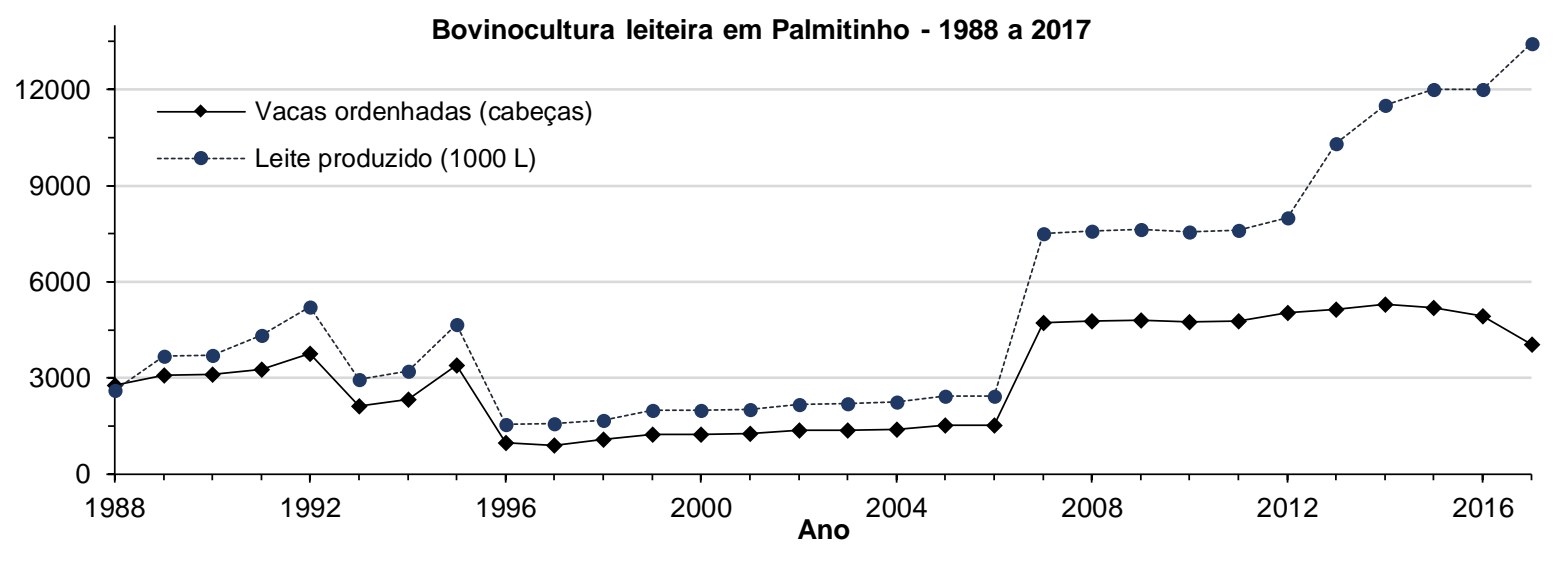

Fonte - PPM / IBGE (1988 a 2017b); Organização: Capoane, V.

A criação de aves para abate em larga escala está presente em 16 propriedades (Figura 5) e, em 2017 o plantel correspondia a 563.500 aves (Figura 7). O período com maior número de aves concentrou-se de 2007 a 2012 e, entre 2012 e 2013 o número de aves diminuiu 57\%, apresentando pequena variação nos anos seguintes. Em 2017 os números voltaram a subir, correspondendo a 38,5\% em relação ao ano de 2016 (Figura 7). O CV no período analisado foi de 78\% (Tabela 2), que indica dispersão muito alta dos dados.

Conforme o Secretário da Agricultura e Meio Ambiente do município de Palmitinho em matéria veiculada na Vitrine do Povo (CASTRO, 2017), a expectativa ao longo do ano de 2017 até o primeiro semestre de 2018 era a de construção de seis a oito modais no município, o que equivaleria a um aumento superior a 250 mil frangos. Ainda, conforme a matéria, esta atividade tornou-se fundamental para a renda de várias famílias do município e, de acordo com o Setor de Tributos, em 2016, o volume de frangos comercializados correspondeu a $14,39 \%$ da produção do município com um total de $\mathrm{R} \$$ $17.779,368$ sendo produzidos 8.539 .284 toneladas de frango. 
Figura 7 - Evolução da avicultura no município de Palmitinho no período de 1988 a 2017.

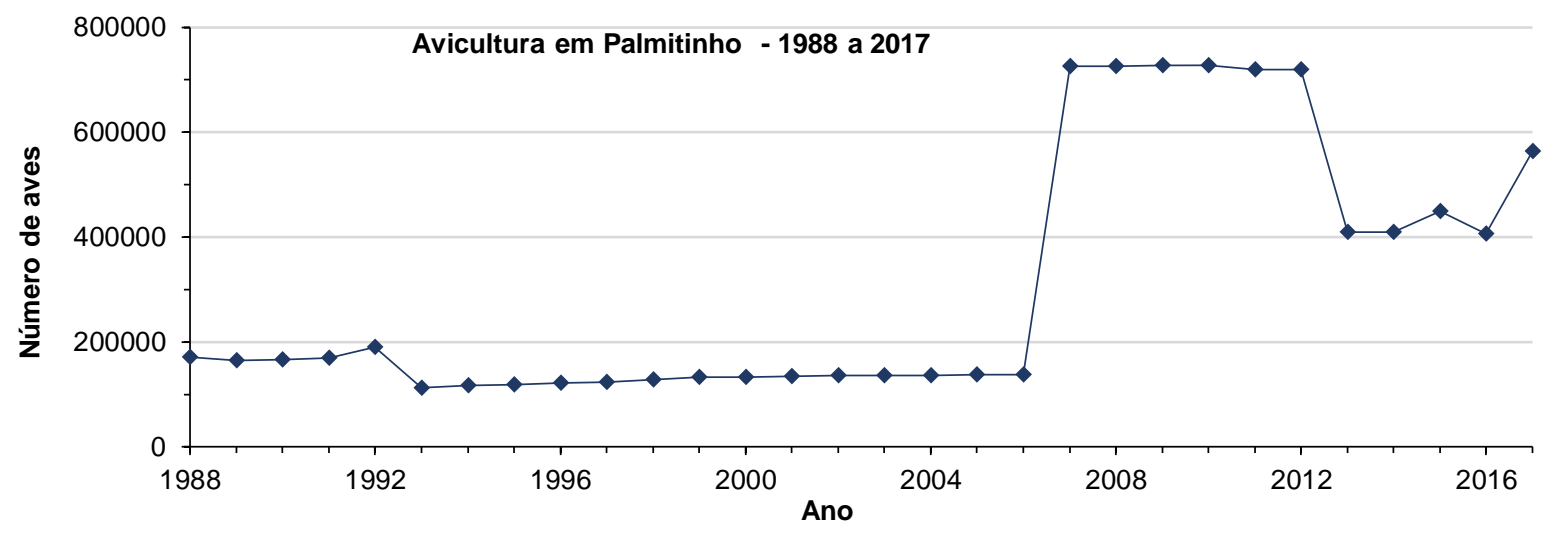

Fonte - PPM / IBGE (1988 a 2017b); Organização: Capoane, V.

Ainda que as atividades de suinocultura, avicultura e produção de leite tenham grande importância econômica e social para o município, a intensificação da produção, principalmente a de suínos, tem provocado uma forte pressão sobre os recursos naturais, especialmente sobre o solo e a água. Conforme Capoane; Costa; Kuplich (2017b), na suinocultura, a problemática reside na dificuldade de se fazer o manejo ambientalmente adequado dos dejetos líquidos que são gerados nos sistemas confinados de produção. Segundo esses autores, a forma predominante de manejo dos resíduos, tanto de suínos quanto de aves, é o seu emprego como fertilizante orgânico em áreas agrícolas. Todavia, no município de Palmitinho predominam pequenas propriedades e, em função da área agrícola reduzida (Figura $8 \mathrm{~A}$ ) e relevo predominante ondulado $(33,4 \%)$ e forte ondulado $(44,8 \%)$ (Figura $8 \mathrm{~B})$, a maioria das propriedades que desenvolvem a suinocultura na forma intensiva não tem condições de realizar a reciclagem dos dejetos sob a forma de fertilizante orgânico. É comum a aplicação sucessiva de efluentes em áreas agrícolas próximas as granjas e, extravasamento das esterqueiras nas épocas que não é possível a aplicação nas lavouras em função do estágio de desenvolvimento das culturas (CAPOANE et al., 2014).

Utilizando o cálculo proposto por Oliveira (1993), o volume de dejetos líquidos produzidos em Palmitinho no ano de 2017 foi de $245.152,3 \mathrm{~m}^{3}$, com uma oferta de $91,3 \mathrm{~m}^{3} \mathrm{ha}^{-1}$ ano-1 para as áreas com culturas temporárias do município (2.685 ha). Em conversas com suinocultores nos trabalhos de campo, constatou-se que a utilização do efluente como fertilizante orgânico fica restrita as propriedades que desenvolvem a atividade e, em propriedades vizinhas, principalmente em função do custo de transporte. Assim, considerando que os solos não são sumidouros infinitos para os nutrientes presentes no efluente como fósforo e nitrogênio, e metais pesados como cobre e zinco, a aplicação continuada a uma taxa que excede as exigidas pelas culturas, contamina os solos (TIECHER et al., 2017) e aumenta sobremaneira os riscos de perdas de nutrientes via erosão hídrica (poluição difusa), o que pode ameaçar a qualidade da água dos mananciais (ASSIS, 2007; KATO; KURODA; NAKASONE, 2009; BROETTO et al., 2014; BOITT et al., 2018).

A análise qualitativa do uso e cobertura da terra (Figura 8A), a partir do NDVI - que é um indicador numérico utilizado para avaliar se o alvo contém vegetação verde viva ou não - mostra que para a data selecionada predominam valores intermediários. A cor azul, valores negativos, representa os corpos d'água; a cor rosa, solo exposto e área urbanizada, a transição da cor rosa amarela indica o menor verdor ou condição crítica de vigor da vegetação, representada pelas áreas agrícolas, a transição da cores amarela para verde representam aumento do vigor da vegetação, onde podem ser englobadas as áreas de pastagens e matas em regeneração. A cor verde-escura representa os valores mais elevados do índice de vegetação, indicando maior vigor, ou seja, os fragmentos florestais representados pela fitofisionomia da Floresta Estacional Decidual. Os fragmentos com baixo grau de antropização encontram-se nas áreas íngremes em função da dificuldade de conversão para agricultura.

Em trabalhos à campo, constatou-se matas em vários estágios de regeneração natural, isso se deve, conforme Capoane et al. (2008), ao êxodo de jovens em busca de melhores oportunidades nas cidades. Dessa forma, os idosos, já sem condições físicas de trabalhar na terra, abandonam a atividade agrícola, 
o que tem possibilitado a regeneração natural de muitas áreas. A fonte de renda nas propriedades formadas por idosos, são as aposentadorias.

Rosa et al. (2017), analisando a dinâmica da cobertura florestal no noroeste do RS entre os anos de 1985 e 2014, a partir de imagens dos sensores multiespectrais do Landsat 5 (TM) e 8 (OLI), constataram um aumento de 50,4\% da área ocupada por florestas nesse período. Os autores atribuem o processo de regeneração florestal, a criação de leis e políticas públicas que promovem a preservação, plantio de espécies exóticas como eucalipto e, da dinâmica demográfica, como constataram Capoane et al. (2008). Nas propriedades que desenvolvem a atividade pecuária, as matas ripárias e fragmentos florestais remanescentes constituem barreiras físicas que impedem ou diminuem a transferência de poluentes dos sistemas terrestres para os aquáticos.

Figura 8 - Índice de vegetação por diferença normalizada (A) e classes de declividade (B) para o município de Palmitinho.

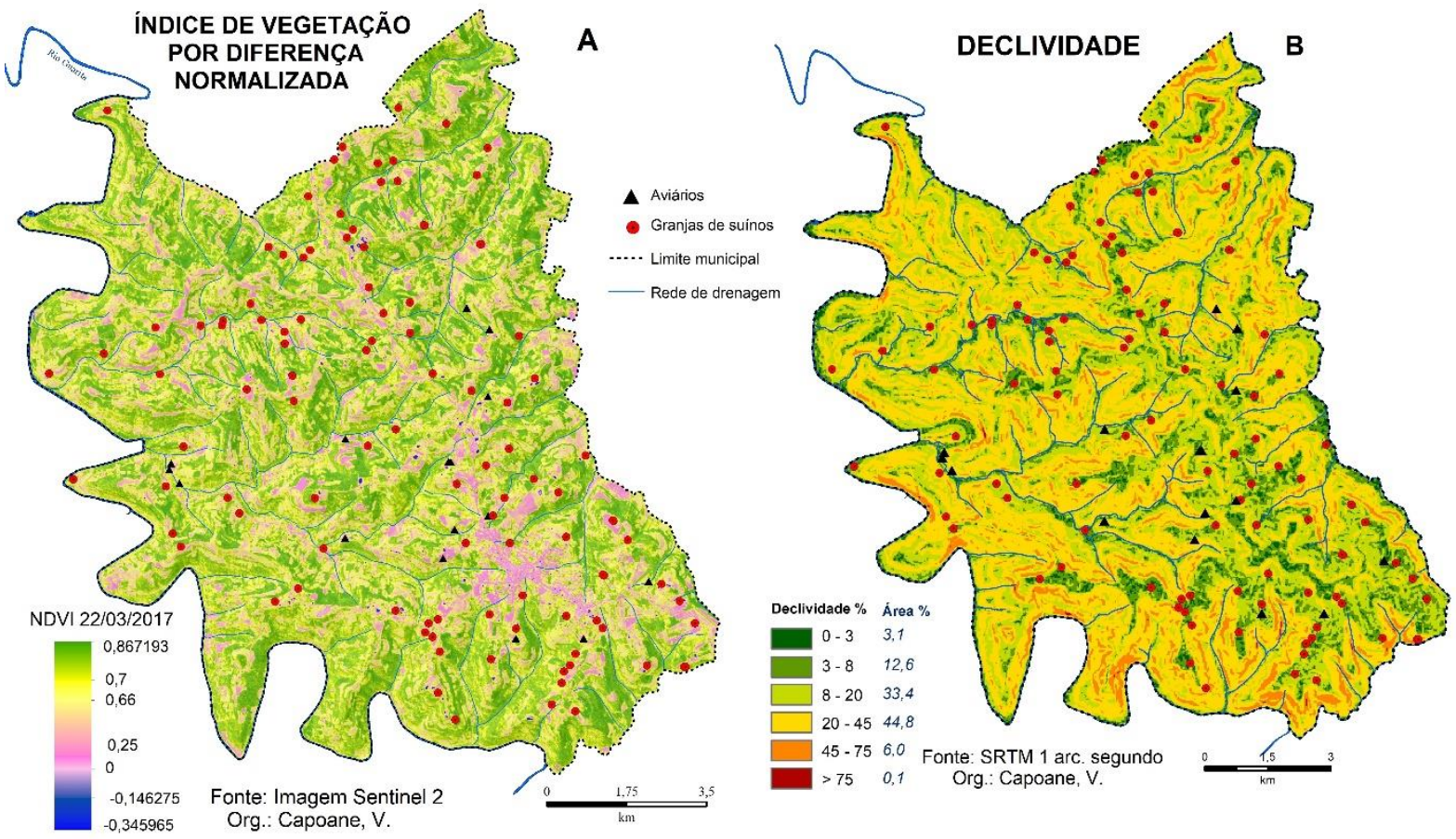

A análise dos dados dos últimos 30 anos para o município de Palmitinho mostra uma migração da atividade de produção de grãos para pecuária intensiva, que são mais lucrativas, principalmente para as pequenas propriedades rurais. Embora isso tenha resultado em receitas para o município e melhorado a qualidade de vida de muitas famílias, a concentração de animais em pequenas áreas, trouxe impactos profundos para a vida dos animais, seres humanos e para o meio ambiente.

Se o modelo a atual de produção, que relega a gestão dos resíduos para o segundo plano, persistir, a tendência é a intensificação da degradação ambiental, afetando cada vez mais a saúde pública pela poluição da água devido à entrada excessiva de nutrientes e pelo uso abusivo de fármacos; do solo pela utilização indiscriminada de efluente líquido como fertilizante e; do ar pela emissão de odores e gases de efeito estufa.

Conforme Capoane et al. (2017c), a sociedade brasileira deve ser informada dos reais impactos ambientais e na saúde humana que a agricultura têm provocado quando mal gerida, para que possa pressionar os órgãos regulamentadores a restringir o uso excessivo de venenos para as plantas; fiscalizar a restauração das áreas de preservação permanente; proibir a implantação de novas granjas em áreas já impactadas, em processo de degradação ou, que apresentem algum risco ambiental, como por exemplo, solos rasos e relevo declivoso, pois a forma como a atividade vem sendo conduzida no Brasil é insustentável ambientalmente.

Embora existam tecnologias como biodigestores que além de diminuírem a emissão de metano, ter potencial energético e melhorar a qualidade do fertilizante, em termos de Brasil, ainda é incipiente nos

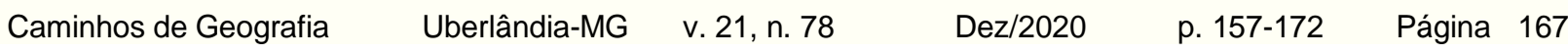


sistemas intensivos de produção animal. Como agravante, conforme Miranda (2005), não existe consenso entre os peritos-técnicos em relação às alternativas tecnológicas mais adequadas a serem utilizadas no enfrentamento da questão ambiental, pois, se para alguns o problema pode ser resolvido através da implementação de medidas tecnológicas, tais como melhoria nas condições de armazenagem e reciclagem dos dejetos, para outros a questão passa por uma completa transformação no atual modelo de produção industrial de suínos, intrinsecamente insustentável com as atuais características da agricultura familiar regional. Assim, a degradação dos recursos naturais e a saúde dos seres vivos tende a aumentar.

\section{CONCLUSÕES}

Neste trabalho objetivou-se analisar a evolução da produção agrícola no período de 1988 a 2017 e os impactos ambientais associados a essa atividade, no município de Palmitinho, RS. Os resultados obtidos mostram que a área utilizada para o plantio de culturas temporárias teve um decréscimo de $87,7 \%$ no período analisado. Parte dessas áreas foram convertidas em pastagens para alimentação do gado leiteiro, o restante há matas em vários estágios de regeneração natural. Das sete principais culturas temporárias do município, apenas o fumo teve aumento na área plantada (13,3\%), as demais culturas apresentaram queda de 95,8, 92,9, 91,0, 89,5, 78,6 e 71,2\%, para cana-de-açúcar, soja, trigo, milho, mandioca e feijão, respectivamente. Em 2017, essas sete culturas correspondiam a $97,1 \%$ da área plantada com lavouras temporárias no município de Palmitinho. Na pecuária, destacam-se a produção de suínos com um plantel de 91.900 animais, a bovinocultura leiteira com 4.050 animais e, avicultura com um plantel de 563.500 aves, em 2017.

Embora as atividades agrícolas tenham grande importância econômica e social, têm provocado uma forte pressão sobre os recursos naturais, principalmente sobre o solo e a água que são impactadas como resultado da erosão do solo e do escoamento contendo fertilizantes (orgânicos e inorgânicos), pesticidas, drogas veterinárias e agentes patogênicos.

\section{REFERÊNCIAS}

ALEXANDRATOS, N.; BRUINSMA, J. World Food and Agriculture to 2030/50: The 2012 Revision. ESA Working Paper n. 12-03. FAO, Rome, Italy, 2012.

ASSIS, F. O.; MURATORI, A. M. Poluição hídrica por dejetos de suínos: um estudo de caso na área rural do município de Quilombo, SC. Revista Geografar (UFPR), Curitiba, v. 2, p. 42-59, jan./jun. 2007. https://doi.org/10.5380/geografar.v2i1.8418

BAILEY, C.; SPIELMEYER, A.; FRINGS, R. M.; HAMSCHER, G.; SCHÜTTRUMPF, H. From agricultural fields to surface water systems: the overland transport of veterinary antibiotics. Journal of Soils and Sediments, Berlin Heidelberg, v. 15, p. 1630-1634, abr. 2015. https://doi.org/10.1007/s11368-015-1140-4

BASSET-MENS, C.; VAN DER WERF, H. M. G. Scenario-based environmental assessment of farming systems: the case of pig production in France. Agriculture, Ecosystems \& Environment, v. 105, p. 127144, jan. 2005. https://doi.org/10.1016/j.agee.2004.05.007

BOITT, G.; SCHMITT, D. E.; GATIBONI, L. C.; WAKELIN, S. A.; BLACK, A.; SACOMORI, W.; CASSOL, P. C.; CONDRON, L. M. Fate of phosphorus applied to soil in pig slurry under cropping in southern Brazil. Geoderma, v. 321, p. 164-172, jul. 2018. https://doi.org/10.1016/j.geoderma.2018.02.010

BOMMARCO, R.; KLEIJN, D.; POTTS, S.G. Ecological intensification: harnessing ecosystem services for food security. Trends in Ecology \& Evolution, v. 28, p 230-288, abr. 2013. https://doi.org/10.1016/j.tree.2012.10.012

BROETTO, T.; TORNQUIST, C. G.; BAYER, C.; CAMPOS, B. C.; MERTEN, C. G.; WOTTRICH, B. Soils and surface waters as affected by long-term swine slurry application in oxisols of southern Brazil. Pedosphere, v. 24, n. 5, p. 585-594, out. 2014. https://doi.org/10.1016/S1002-0160(14)60044-8 
CAPOANE, V.; CASALI, C. A.; SILVÉRIO DA SILVA, J. L.; SANTOS, D. R. Danos ambientais ocasionados pela atividade suinícola na microbacia hidrográfica do Arroio Caldeirão, Palmitinho - RS. Geografia. Ensino \& Pesquisa, Santa Maria, v. 10, p. 506-520, 2008.

CAPOANE, V.; TIECHER, T.; SCHAEFER, G. L.; SANTOS, D. R. Impactos da suinocultura na qualidade da água da bacia hidrográfica do Arroio Caldeirão, Palmitinho, Rio Grande do Sul. Brazilian Geographical Journal: geosciences and humanities research medium, Ituiutaba, v. 5, n. 2, p. 494-509, 2014.

CAPOANE, V. Determinação do índice de potência de escoamento para o município de Palmitinho/RS utilizando modelos digitais de elevação. Estudos Geográficos (UNESP), Rio Claro, v. 13, p. 106-117, 2015.

CAPOANE, V.; TIECHER, T.; SCHAEFER, G. L.; ALVAREZ, J. W. R.; SANTOS, D. R. Avaliação da qualidade dos sedimentos de leito em uma bacia hidrográfica do noroeste do Rio Grande do Sul. Boletim Gaúcho de Geografia, Porto Alegre, v. 42, p. 1-23, 2016.

CAPOANE, V.; COSTA, L. F. F.; KUPLICH, T. M. Efeito da resolução de modelos digitais de elevação na derivação do índice topográfico de umidade: estudo de caso no município de Palmitinho-RS. Geografia em Questão, Marechal Cândido Rondon, v. 10, p. 9-23, 2017a.

CAPOANE, V.; COSTA, L. F. F.; KUPLICH, T. M. Identificação das áreas susceptíveis a transferência de poluentes para os sistemas aquáticos utilizando álgebra de mapas. Caminhos de Geografia, Uberlândia, v. 18, n. 62, p. 114-124, 2017b. https://doi.org/10.14393/RCG186210

CAPOANE, V.; TIECHER, T.; ZAFAR, M.; SANTOS, D. R. Impacto da atividade de suinocultura intensiva na qualidade da água de uma bacia hidrográfica do médio alto Uruguai. In: TIECHER, T. (Org.). Manejo e conservação do solo e da água em pequenas propriedades rurais no sul do Brasil: impacto das atividades agropecuárias na contaminação do solo e da água. 1ed. Frederico Westphalen: URI, 2017c, v. 1, p. 162-182.

CASALI, M. S. O sistema agroindustrial do leite do Rio Grande do Sul e a estrutura de governança nas transações com leite em Cruz Alta - RS. Dissertação (Mestrado em Administração) - Santa Maria: UFSM. 2012.

CASTRO, D. Avicultura deve ter investimento de cerca $R \$ 3,5$ Milhões em Palmitinho. Vitrine do Povo, Palmitinho 19 agos. 2017. Disponível em: https://www.vitrinedopovo.com.br/singlepost/2017/08/25/Avicultura-deve-ter-investimento-de-cerca-R-35-Milh\%C3\%B5es-em-Palmitinho.

Acesso em: 19 jan. 2019.

CONRAD, O.; BECHTEL, B.; BOCK, M.; DIETRICH, H.; FISCHER, E.; GERLITZ, L.; WEHBERG, J.; WICHMANN, V.; BÖHNER, J. System for Automated Geoscientific Analyses (SAGA) v. 2.1.4, Geoscientific Model Development, v. 8, 1991-2007, 2015. https://doi.org/10.5194/gmd-8-1991-2015

CONTI, L.; CERETTA, C. A.; FERREIRA, P. A. A.; LOURENZI, C. R.; GIROTTO, E.; LORENSINI, F.; TIECHER, T. L.; MARCHEZAN, C.; ANCHIETA, M. G.; BRUNETTO, G. Soil solution concentrations and chemical species of copper and zinc in a soil with a history of pig slurry application and plant cultivation. Agriculture, Ecosystems \& Environment, v. 216, p. 374-386, jan. 2016. https://doi.org/10.1016/j.agee.2015.09.040

CUNHA, N. G.; SILVEIRA, R. J. C.; KOESTER, E.; OLIVEIRA, L. D.; ALBA, J. M. F.; COSTA, F. A.; TERRES, V. C.; LOPES, R. T. Estudos de Solos do Município de Palmitinho, RS. Documentos (Circular Técnica, Embrapa Clima Temperado), v. 105, p. 1-28, 2010.

DIAS, A. A.; PARISI, G. N. Programa Geologia do Brasil, Projeto Geologia para Apoio aos Arranjos Produtivos de Gemas do Rio Grande do Sul, RS; Frederico Westphalen, folha SG.22-Y-C-II. Porto Alegre: CPRM, 2007. $73 \mathrm{p}$.

EMBRAPA - Empresa Brasileira de Pesquisa Agropecuária. Centro Nacional de Pesquisa em Solos. Sistema Brasileiro de Classificação de Solos. Brasília, 2006. 
ESA - European Spatial Agency. Mission: Sentinel-2. Cena R124 de 22/03/2017. Disponível em: https://scihub.copernicus.eu/dhus/\#/home. Acesso em: 11 abr. 2020.

FAO - Food and Agriculture Organization. Faostat. Disponível em: http://www.fao.org/faostat/en/\#data/RL/visualize. Acesso em: 09 jan. 2019.

The state of food in agriculture: Livestock in the balance. Rome, Italy: Electronic Publishing Policy and Support Branch-Communication Division. Food and Agriculture Organization of the United Nations (FAO), Italy. 2009.

FOLEY, J. A.; DEFRIES, R.; ASNER, G. P.; BARFORD, C.; BONAN, G.; CARPENTER, S. R.; CHAPIN, F. S.; COE, M. T.; DAILY, G. C.; GIBBS, H. Q.; HELKOWSKI, J. H.; HOLLOWAY, T.; HOWARD, H. A.; KUCHARIK, C.J .; MONFREDA, C.; PATZ, J. A.; PRENTICE, I. C.; RAMANKUTTY, N.; SNYDER, P. K. Global consequences of land use. Science, v. 309, p. 570-574, agos. 2005. https://doi.org/10.1126/science.1111772

FOLEY, J. A.; RAMANKUTTY, N.; BRAUMAN, K. A.; CASSIDY, E. S.; GERBER, J. S.; JOHNSTON, M.; MUELLER, N. D.; O'CONNELL, C.; RAY, D. K.; WEST, P. C.; BALZER, C.; BENNETT, E. M.; CARPENTER, S. R.; HILL, L.; MONFREDA, C.; POLASKY, S.; ROCKSTRÖM, J.; SHEEHAN, J.; SIEBERT, S.; TILMAN, D.; ZAKS, D. P. Solutions for a cultivated planet. Nature, v. 478, p. 337-342, out. 2011. https://doi.org/10.1038/nature10452

GERBER, P. J.; STEINFELD, H.; HENDERSON, B.; MOTTET, A.; OPIO, C.; DIJKMAN, J.; FALCUCCI, A.; TEMPIO, G. Tackling Climate Change through Livestock-A Global Assessment of Emissions and Mitigation Opportunities; Food and Agriculture Organization of the United Nations: Rome, Italy. 2013.

HAMMER, O.; HARPER, D.A.; RYAN, P.D. Past - Paleontological Statistics ver.1.12. 2013. Disponível em: <http://www.folk.uio.no/ohammer/past>. Acesso em: 20 fev. 2019.

IBGE - Instituto Brasileiro de Geografia e Estatística. Produção Agrícola Municipal - 1988 a 2017a. Disponível em: https://sidra.ibge.gov.br/tabela/1612. Acesso em: 20 jul. 2019.

Produção Pecuária Municipal - 1988 a 2017b. Disponível em: https://sidra.ibge.gov.br/pesquisa/ppm/tabelas/brasil/2018. Acesso em: 20 jul. 2019.

Mapa de Biomas do Brasil. 2006. Disponível em: https://www.ibge.gov.br/geociencias/informacoes-ambientais/15842-biomas.html?=\&t=downloads. Acesso em: 20 jul. 2019.

\section{Censo}

Demográfico

2010.

Disponível

em:

http://www.censo2010.ibge.gov.br/sinopse/index.php?dados=8. Acesso em: 20 jul. 2019.

Base cartográfica contínua do Brasil, ao milionésimo. 2016 Disponível em: https://www.ibge.gov.br/geociencias/downloads-geociencias.html. Acesso em: 20 jul. 2019.

KATO, T.; KURODA, H.; NAKASONE, H. Runoff characteristics of nutrients from an agricultural watershed with intensive livestock production. Journal of Hydrology, v. 368, n. 1-4, p. 79-87, abr. 2009. https://doi.org/10.1016/i.jhydrol.2009.01.028

LEWIS, R. A. CRC Dictionary of agricultural sciences. 2. ed. Boca Raton, Florida: CRC Press, 2001. https://doi.org/10.1201/9781482274509

MARASCHIN, A. F. As relações entre produtores de leite e cooperativas: um estudo de caso na bacia leiteira de Santa Rosa - RS. Dissertação (Mestrado em Desenvolvimento Rural) - Porto Alegre: UFRGS. 2004.

MAZOYER, M.; ROUDART, L. História das agriculturas no mundo: do neolítico à crise contemporânea. São Paulo: UNESP; Brasília: NEAD, 2009. 
MEKONNEN, M. M.; HOEKSTRA, A.Y. A global assessment of the water footprint of farm animal products. Ecosystems, v. 15, p. 401-415, jan. 2012. https://doi.org/10.1007/s10021-011-9517-8 https://doi.org/10.1007/s10021-011-9517-8

MENZI, H.; OENEMA, O.; BURTON, C.; SHIPIN, O.; GERBER, P. Impacts of intensive livestock production and manure management on the environment. In: STEINFELD, H.; MOONEY, H. A.; SCHNEIDER, F.; NEVILLE, L. E. (Eds). Livestock in a changing landscape, drivers, consequences, and responses, Island Press, USA, 2010. pp. 139-163.

MILANI, M.P. Qualidade do leite em diferentes sistemas de produção, anos e estações climáticas no Noroeste do Rio Grande do Sul. Dissertação (Mestrado em Ciência e Tecnologia de Alimentos) - Santa Maria: UFSM. 2011.

MIRANDA, C. R. de. Avaliação de estratégias para sustentabilidade da suinocultura. Tese (Doutorado em Engenharia Ambiental) - Florianópolis: UFSC. 2005.

OLIVEIRA, A. de. O padrão tecnológico na produção de leite e o desenvolvimento rural: uma análise baseada nos sistemas de produção do município de ljuí (RS). Dissertação (Mestrado em Desenvolvimento) - ljuí: UNIJUI. 2010.

OLIVEIRA, P. A. V. Manual de utilização dos dejetos de suínos. Concórdia-SC: EMBRAPA-CNPSA, 1993.

PIMENTEL-GOMES, F. Curso de Estatística Experimental. 12. ed. Piracicaba: Livraria Nobel. 1985. $467 p$.

RAN, Y.; MIDDELAAR, VAN C. E.; LANNERSTAD, M.; HERRERO, M.; BOER, I. J. M. Freshwater use in livestock production: To be used for food crops or livestock feed? Agricultural Systems, v. 155, p. 18, jul. 2017. https://doi.org/10.1016/j.agsy.2017.03.008

ROSA, P. A.; BREUNIG, F. M.; ALMEIDA, C.; BALBINOT, R. Dinâmica de fragmentos florestais no noroeste do Rio Grande do Sul. Geografia Ensino \& Pesquisa, Santa Maria, v. 21, p. 177-189, jan./abr. 2017. https://doi.org/10.5902/2236499424059

ROSSATO, M. S. Os climas do Rio Grande do Sul: variabilidade, tendências e tipologia. Tese (Doutorado em Geografia) - Porto Alegre: UFRGS. 2011.

SILVEIRA, R. L. L. da. A cultura do tabaco na Região Sul do Brasil: dinâmica de produção, organização espacial e características socioeconômicas. Geografia Ensino \& Pesquisa, Santa Maria, v. 19, n. 2, maio/agos. 2015.

SILVEIRA, R. L. L. da. Rede agroindustrial do tabaco e a dinâmica de organização espacial e de usos do território na região Sul do Brasil. Relatório Final de Pesquisa. Santa Cruz do Sul: CNPq/UNISC, janeiro, 2011. $170 \mathrm{p}$.

SMAMA - SECRETARIA MUNICIPAL DA AGRICULTURA E MEIO AMBIENTE. Município de Palmitinho, Portal do Cidadão. 2018.2 Disponível em: https://palmitinho.atende.net/\#!/tipo/pagina/valor/13. Acesso em: 20 out. 2018.

SNAP - Sentinel Application Platform. SNAP Download, version 7.0.0. Disponível em: https://step.esa.int/main/download/snap-download/. Acesso em: 28 jul. 2019.

SONKA, S. T. Big Data: fueling the next evolution of agricultural innovation. Journal of Innovation Management, London, v. 4, n. 1, p. 114-136, maio 2016. https://doi.org/10.24840/21830606004.0010008

SOS MATA ATLÂNTICA/INPE. Atlas dos remanescentes florestais da Mata Atlântica período 20162017. Relatório técnico. 2018.2 Disponível em: http://mapas.sosma.org.br/site_media/download/Atlas_Mata_Atlantica_2016-

2017_relatorio_tecnico_2018_final.pdf. Acesso em: 19 jan. 2019. 
STEINFELD, H.; GERBER, P.; WASSENAAR, T.; CASTEL, V.; ROSALES, M.; et al. Livestock's long shadow: environmental issues and options. Food and Agriculture Organization of the United Nations (FAO), Rome, Italy. 2006.

TIECHER, T.; TIECHER, T. L.; MALLMANN, F. J. K.; ZAFAR, M.; CERETTA, C. A.; LOURENZI, C. R. BRUNETTO, G.; GATIBONI, L. C.; SANTOS, D. R. Chemical, Biological, and Biochemical Parameters of the Soil P Cycle After Long-Term Pig Slurry Application in No-Tillage System. Revista Brasileira de Ciência do Solo, Viçosa, v. 41, p. 1, 2017. https://doi.org/10.1590/18069657rbcs20170037

TILMAN, D.; BALZER, C.; HILL, J.; BEFORT, B. L. Global food demand and the sustainable intensification of agriculture. Proceedings of the National Academy of Sciences, Washington, D.C., v. 108, p. 20260-20264, dez. 2011. https://doi.org/10.1073/pnas.1116437108

TRINDADE, C, S da; BEPPLER, L, S. Análise das vantagens comparativas e orientação regional das exportações do tabaco brasileiro entre 2006 e 2016. Revista Estudo \& Debate, Lajeado, v. 27, n. 1, 2020. https://doi.org/10.22410/issn.1983-036X.v27i1a2020.2306

TURCOTTE, M. M.; ARAKI, H.; KARP, D. S.; POVEDA, K.; WHITEHEAD, S. R. The eco-evolutionary impacts of domestication and agricultural practices on wild species. Philosophical Transactions of the Royal Society B, v. 372, p. 1-9, jan. 2017. https://doi.org/10.1098/rstb.2016.0033

USGS - United States Geological Survey. Digital Elevation, SRTM, 1 Arc-Second Global. Disponível: https://earthexplorer.usgs.gov/. Acesso: 23 nov. 2019.

VENGLOVSKY, J.; SASAKOVA, N.; PLACHA, I. Pathogens and antibiotic residues in animal manures and hygienic and ecological risks related to subsequent land application. Bioresource Technology, v. 100, n. 22, p. 5386-5391, nov. 2009. https://doi.org/10.1016/i.biortech.2009.03.068

Recebido em: 10/03/2020

Aceito para publicação em: 30/06/2020 